Available online on 15.09.2020 at http://ujpr.org
Universal Journal of Pharmaceutical Research
An International Peer Reviewed Journal
Open access to Pharmaceutical research is an open access article distributed under the terms of the Creative Commons Attribution-Non
Commercial Share Alike 4.0 License which permits unrestricted non commercial use,
provided the original work is properly cited
Volume 5, Issue 4, 2020

\title{
PREVALENCE OF PREMATURE LOSS OF PRIMARY TEETH AT THE AGE OF 6-10 YEARS IN SANA'A CITY, YEMEN
}

Kadija Ahmed Omer Bamashmoos ${ }^{1}\left(\mathbb{D}\right.$, Abdalhaq Hussin Alhasani ${ }^{2}{ }^{\oplus}$, Ameen Abdullah Yahya AlAkwa $^{2}$, Abdul Qader Mohammed Qasem Zabara1 ${ }^{\circledR}$, Hassan Abdul wahab Al-Shamahy ${ }^{3}{ }^{\mathbb{D}}$, Hussein Mohammad Shoga Al-deen ${ }^{2}$ (D), Mohammed A Al-labani ${ }^{2}$

${ }^{1}$ Orthodontics, Pedodontics and Prevention Department Faculty of Dentistry, Sana'a University, Yemen.

${ }^{2}$ Orthodontics, Pedodontics and Prevention Department Faculty of Dentistry, Ibb University, Yemen. ${ }^{3}$ Departement of Basic Sciences, Faculty of Dentistry, Sana' a University, Republic of Yemen.

\section{ABSTRACT}

Background and Objectives: Primary teeth and the integrity of the primary teeth are very important for the normal growth and progress of the occlusal relationships and the dentofacial structures. Premature loss of the primary teeth may lead to the loss of the arch length needed for the eruption of permanent teeth and thus lead to rotation, crowding, and impaction of permanent teeth. This study aimed to determine the prevalence of premature loss of primary teeth among children aged 6-10 years in Sana'a city, Yemen. Materials and methods: This observational cross-sectional study included 1091 children, aged 6-10 years. An experienced examiner the first author carried out all clinical examinations under natural light. Data were collected including age and missing teeth.

Results: The results showed that $26 \%$ of the sample suffered premature loss of primary teeth with no significant difference between the sexes $(P>0.05)$. There was low in prevalence of premature loss of primary teeth in 10 years $(17.7 \%)$, while the rate raised to $29.7 \%, 31.6 \%$, and $31.7 \%$ in 6,7 and 9 years respectively. When considering the number of teeth, the prevalence of one premature loss was $10.8 \%$, followed by two premature losses $(9.8 \%)$, while the loss rate of 3 or more was $5.4 \%$. Considering dental arch $61.8 \%$ of loss was Mandible loss, while the loss in Maxilla was $38.1 \%$ only. The most common missing tooth is the first lower right primary molar (17\%).

Conclusion: The prevalence of premature loss in current study is similar to that of developing countries, the rate was low at 10 years for children, while the rate increased at 6,7 and 9 years; most of the loss was in the lower jaw and the most common missing tooth was the right lower primary molar. This result determines the importance of increasing awareness of this problem and focusing on the need for more preventive efforts to maintain healthy and natural teeth that improve the chewing function and aesthetic appearance of children and the entire population.

Keywords: Children, prevalence, premature loss, primary teeth, Sana'a city, Yemen.

Article Info: Received 23 June 2020; Revised 19 July; Accepted 26 August, Available online 15 September 2020

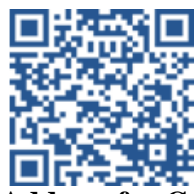

Cite this article-

Bamashmoosm KAO, Alhasani AH, Al-Akwa AAY, Zabara AQMQ, Al-Shamahy HA, Al-deen HMS, Al-labani MA. Prevalence of premature loss of primary teeth at the age of 6-10 years in Sana'a city, Yemen. Universal Journal of Pharmaceutical Research 2020; 5(4):42-46.

Address for Correspondence

Prof. Hassan A. Al-Shamahy, Faculty of Medicine and Health Sciences, Sana'a University, P.O. Box 775 Sana'a, Yemen. Tel: +967-1-239551, E-mail: shmahe@yemen.net.ye

\section{INTRODUCTION}

Dental research is still limited in studying dental problems in Yemen, however some recent studies have been conducted that discussed the prevalence of malocclusion, the causes of permanent tooth extraction in general dental practices, the spread of the retromolar canal, and the prevalence and causes of traumatic dental injuries ${ }^{1-4}$. The primary teeth and the integrity of the primary teeth are very important for the normal growth and progress of the occlusal relationships and dentofacial structures. Preserving the primary teeth until they are naturally exfoliated is one of the most important goals of pediatric dentistry ${ }^{5}$. An early or premature loss is known as the loss of a primary tooth before the time of natural exfoliation ${ }^{5,6}$. Early loss of primary teeth is a public health problem. A tooth is lost prematurely if it is lost from a dental arch within a year before the normal age of exfoliation ${ }^{7}$. There are local and systemic factors that cause early loss of primary teeth. Local factors include tooth decay, which is the most common cause, inadequate nutrition, bad oral health, trauma, periodontal disease and premature root 
resorption ${ }^{8-10}$. There are a number of systemic diseases such as diabetes, phosphate deficiency, leukemia, hyperthyroidism, etc., whose effects on the oral cavity may make the teeth subject to exfoliation ${ }^{11}$. It is generally accepted that premature loss of deciduous teeth is associated with malocclusion of permanent dentations, such as tooth rotation, extrusion of antagonist teeth, dental crowding, development of habits, and disorders of craniofacial development, especially post-dental impaction and reduction of the length of the dental $\operatorname{arch}^{12-14}$. Early loss of the primary teeth leads to early or late eruption of successor teeth ${ }^{10}$. The reason for choosing this topic is to determine the prevalence of early loss of primary teeth in Yemen, as this is of importance in preventive treatment planning and shows the extent of the need to spread knowledge of such a problem between the medical community and society in general.

\section{SUBJECTS AND METHODS}

Study Design: A cross sectional study was conducted. Study Population: The target population was students of both genders, aged 6 to 10 years, chosen from public and private primary schools that are located in the five districts.

All children should match the study inclusions criteria a) 6 to10 years old, b) a tooth was considered to be prematurely lost if it was missing from the dental arch one year before its natural age of exfoliation ${ }^{15}$, and c) The study subjects provided informed consent from their parents and presented for examination on the day of screening. However, the exclusions criteria included: a) Non-Yemeni children and b) medically compromised children.

Sample size: The sample size was calculated using EPI version 7, based on the following assumptions: a) The total number of students in the five Sana'a City districts is 101,590 according to the Ministry of Education; b) The previous recurrence of early loss of primary teeth is estimated to be approximately $51 \%$, with a $99.9 \%$ confidence level and with a margin error of 0.01 . From previous assumptions, 1091 participants are needed to give significant results out of the total population.

Study area and sampling type: Multistage sampling method which the first Stage: from the ten districts we chosen randomly five districts: from the south Alsabein district, from the north Al-Thwarh district, from the west Azal district and Al- wahda; and from the middle the Old Sana'a district. The second stage: In each district, we considered that all private and public schools are included in the study, then we randomly selected sixteen public schools and ten private schools which represent nearly $10 \%$ of total number of schools according to Education, 2018. The Third stage: In all randomly selected school, we considered that all the classes of students aged from 6 to 10 years old are included in the study. Then we randomly selected one class from each level. Finally, selection from the selected classes was systemically random; so that we can reach the sample size target.

Data collection and clinical examination: An experienced examiner the first author performed all clinical examinations under natural light. Data including age and missing tooth was collected.

Ethical consideration: The study was approved by the research ethics committee of Faculty of Dentistry, University of Sana'a.

Statistical analysis: Data were analyzed statistically using SPSS 21. Data were presented using tables. The percentage (\%) was used to describe the qualitative variables. Pearson's Chi-Square test was used to show the significance of the association between outcomes at a significance level less than $0.05(\mathrm{P})$.

Table 1: The age and sex distribution of children aged 6-10 years examined for the prevalence of premature loss of primary teeth in Sana'a city, Yemen.

\begin{tabular}{ccccccc}
\hline \multirow{2}{*}{$\begin{array}{c}\text { Age in } \\
\text { years }\end{array}$} & \multicolumn{9}{c}{ Gender } \\
\cline { 2 - 7 } & \multicolumn{2}{c}{ Female } & \multicolumn{2}{c}{ Male } & \multicolumn{2}{c}{ Total } \\
\cline { 2 - 7 } & $\mathbf{N}$ & $\mathbf{\%}$ & $\mathbf{N}$ & $\mathbf{\%}$ & $\mathbf{N}$ & $\mathbf{\%}$ \\
\hline 6 & 62 & 11.6 & 56 & 9.9 & 118 & 10.8 \\
7 & 125 & 23.5 & 103 & 18.3 & 228 & 20.9 \\
8 & 130 & 24.5 & 138 & 24.5 & 268 & 24.6 \\
9 & 123 & 23.2 & 123 & 21.9 & 246 & 22.5 \\
10 & 90 & 16.9 & 141 & 25.1 & 231 & 21.2 \\
Total & 530 & 48.6 & 561 & 51.4 & 1091 & 100 \\
\hline
\end{tabular}

Table 2: Prevalence of premature loss of primary teeth among different ages and sex.

\begin{tabular}{|c|c|c|c|c|c|c|c|c|c|c|c|c|}
\hline \multicolumn{13}{|c|}{ Prevalence of premature loss of primary teeth } \\
\hline Ages & \multicolumn{2}{|c|}{6 years old } & \multicolumn{2}{|c|}{7 years old } & \multicolumn{2}{|c|}{8 years old } & \multicolumn{2}{|c|}{9 years old } & \multicolumn{2}{|c|}{10 years old } & \multicolumn{2}{|c|}{ Total } \\
\hline Gender & $\mathbf{N}$ & $\%$ & $\mathbf{N}$ & $\%$ & $\mathbf{N}$ & $\%$ & $\mathbf{N}$ & $\%$ & $\mathbf{N}$ & $\%$ & $\mathbf{N}$ & $\%$ \\
\hline Males & $17 / 56$ & 30.4 & $32 / 103$ & 31.1 & $29 / 138$ & 21 & $41 / 123$ & 33.3 & 28/141 & 19.8 & $47 / 561$ & 26.2 \\
\hline Females & $18 / 62$ & 29 & $40 / 125$ & 32 & $29 / 130$ & 22.3 & $37 / 123$ & 30.1 & $13 / 90$ & 14.4 & $137 / 530$ & 25.8 \\
\hline Total & $35 / 118$ & 29.7 & $72 / 228$ & 31.6 & $58 / 268$ & 21.6 & $78 / 246$ & 31.7 & $41 / 231$ & 17.7 & $284 / 1091$ & 26 \\
\hline
\end{tabular}

\section{RESULTS}

The result revealed that of the 1091 children included in this study group, $284(26 \%)$ had a premature loss of their primary teeth (Table 1). Both males and females had roughly the same prevalence: $26.2 \%$ and $25.8 \%$, respectively. There was a significant $(p<0.05)$ decrease in the prevalence of premature loss of primary teeth at 10 years $(17.7 \%)$, while the rate increased nonsignificantly to $29.7 \%, 31.6 \%$, and $31.7 \%$ in children aged 6, 7 and 9 years, respectively (Table 2). The results showed that a total of 543 primary teeth were 
lost prematurely. The most commonly lost tooth was 84 (mandibular right first primary molar) with significant rate $(17 \%)$ of the total $(p<0.05)$, followed by 74 (mandibular left first primary molar) with $(16 \%)$ $(p<0.05), 54$ (maxillary right first primary molar) with $(14 \%)(p<0.05)$, then $13 \%$ for teeth numbers 85,75 and $64(p<0.05)$ ( mandibular right and left second primary molar and maxillary left primary molar respectively) (Table 3). When considering the number of teeth, the prevalence of one premature loss was $10.8 \%$, followed by two premature loss $(9.8 \%)$, while 3 or more loss was $5.4 \%$ and the variation was not statistically significant (Table 4).

Table 3: Distribution of premature loss of primary teeth according to the site number of the teeth among male and female children aged 6-10 years.

\begin{tabular}{ccccccc}
\hline \multirow{2}{*}{$\begin{array}{c}\text { Tooth site } \\
\text { numbers }\end{array}$} & \multicolumn{6}{c}{ Gender } \\
\cline { 2 - 7 } & Fumber & \% & Number & \% & Number & \% \\
\cline { 2 - 7 } 51 & 0 & 0.0 & 1 & 0.2 & 1 & 0.2 \\
52 & 0 & 0.0 & 1 & 0.2 & 1 & 0.2 \\
53 & 1 & 0.2 & 2 & 0.4 & 3 & 1 \\
54 & 34 & 6.3 & 44 & 8.1 & 78 & 14 \\
55 & 10 & 1.8 & 19 & 3.5 & 29 & 5 \\
61 & 1 & 0.2 & 1 & 0.2 & 2 & 0.4 \\
62 & 1 & 0.2 & 1 & 0.2 & 2 & 0.4 \\
63 & 1 & 0.2 & 1 & 0.2 & 2 & 0.4 \\
64 & 28 & 5.2 & 42 & 7.7 & 70 & 13 \\
65 & 11 & 2.0 & 8 & 1.5 & 19 & 3 \\
71 & 0 & 0.0 & 0 & 0.0 & 0 & 0.0 \\
72 & 0 & 0.0 & 0 & 0.0 & 0 & 0.0 \\
73 & 5 & 0.9 & 1 & 0.2 & 6 & 1 \\
74 & 37 & 6.8 & 50 & 9.2 & 87 & 16 \\
75 & 31 & 5.7 & 41 & 7.6 & 72 & 13 \\
81 & 0 & 0.0 & 0 & 0.0 & 0 & 0.0 \\
82 & 0 & 0.0 & 0 & 0.0 & 0 & 0.0 \\
83 & 5 & 0.9 & 2 & 0.4 & 7 & 1 \\
84 & 40 & 7.4 & 52 & 9.6 & 92 & 17 \\
85 & 37 & 6.8 & 35 & 6.4 & 72 & 13 \\
Total & 242 & 44.5 & 301 & 55.4 & 543 & 100 \\
\hline
\end{tabular}

Table 4: The number of lost premature primary teeth among male and female children aged 6-10 years.

\begin{tabular}{lcccccc}
\hline \multirow{2}{*}{$\begin{array}{c}\text { Number of lost } \\
\text { teeth }\end{array}$} & \multicolumn{2}{c}{ Male (561) } & \multicolumn{2}{c}{ Female (530) } & \multicolumn{2}{c}{ Total n=1091 } \\
\cline { 2 - 7 } & $\mathbf{N}$ & $\mathbf{\%}$ & $\mathbf{N}$ & $\mathbf{\%}$ & $\mathbf{N}$ & $\mathbf{\%}$ \\
\hline One tooth & 58 & $10.3 \%$ & 60 & $11.3 \%$ & 118 & $10.8 \%$ \\
Two teeth & 53 & $9.5 \%$ & 54 & $10.2 \%$ & 107 & $9.8 \%$ \\
Three and more teeth & 36 & $6.4 \%$ & 23 & $4.3 \%$ & 59 & $5.4 \%$ \\
& 147 & $26.2 \%$ & 137 & $25.8 \%$ & 284 & $26 \%$ \\
\hline
\end{tabular}

Considering the dental arch a significant rate equal to $30.8 \%$ of the loss was the mandible $(\mathrm{p}<0.05)$, while loss in Maxilla was 19\% only (Table 5). Table 6 shows the distribution of premature loss according to dental quadrant among male and female children aged 6-10 years. The result showed that the mandibular right side had the highest incidence of the early loss (15.7\%), followed by the incidence of early loss on the mandibular left side $(15.1 \%)$, then the incidence of early loss on the maxillary right side was $10.3 \%$ and the incidence of early loss on the maxilla left was $8.7 \%$, and the differences were statistically nonsignificant.

Table 5: Distribution of premature loss of primary teeth according to dental arch among male and female children aged 6-10 years.

\begin{tabular}{lcccccc}
\hline Dental arch & \multicolumn{6}{c}{ Gender } \\
\cline { 2 - 7 } & \multicolumn{2}{c}{ Male $(\mathbf{n}=\mathbf{5 6 1})$} & \multicolumn{2}{c}{ Female $(\mathbf{n}=\mathbf{5 3 0})$} & \multicolumn{2}{c}{ Total $(\mathbf{n = 1 0 9 1})$} \\
\cline { 2 - 7 } & Number & \% & Number & \% & Number & \% \\
\hline Maxilla & 120 & 39.9 & 87 & 16.4 & 207 & 38.1 \\
Mandible & 181 & 60.1 & 155 & 29.2 & 336 & 61.8 \\
Total & 301 & 53.6 & 242 & 45.7 & 543 & 100.0 \\
\hline
\end{tabular}

\section{DISCUSSION}

Premature loss of primary teeth is the most common local factor that leads to malocclusion. Many practitioners prefer to extract the primary teeth rather than treat them because it is often complicated ${ }^{16}$. On the other hand, most parents believe that it is not necessary to treat the primary teeth because they will be replaced in any way ${ }^{16}$. The harmony of the permanent teeth interferes with the premature loss of the primary tooth and the main effect of this loss is the congestion caused by the migration of the adjacent teeth $^{13,17}$. Knowledge of the pattern and causes of tooth 
extraction will increase the knowledge of the dental practitioner in order to provide better information about the prevalence of dental disease, availability of dental care, and behaviors towards tooth mortality ${ }^{18-20}$. Of the 1091 children, 284 (26\%) had premature loss of primary teeth in current study which corresponds to $(28.3 \%)$ of children in a study conducted in Mexico by Galicia-Sosa et al., ${ }^{21},(24.9 \%)$ in a study conducted in Brazil by Cavalcanti et al., ${ }^{6}$ and $(25.3 \%)$ in a study conducted in Lacey Romania by Petcu et al., ${ }^{22}$. Compared to other studies conducted in Saudi Arabia, Yemen and Denmark, early loss of primary teeth was $(51 \%),(40.5 \%)$ and $(47.3 \%)$ respectively and it is higher than this study ${ }^{5,23,24}$. This difference may be due to the higher rate of decaying deciduous teeth. In general, the increase in the rate of early loss of primary teeth may be a result of parents and dentists believing that prevention and treatment of a primary tooth is unnecessary because the teeth will eventually be extracted. Some socio-demographic variables in this study showed that there was no statistically significant difference in premature loss of primary teeth between boys and girls. This result was similar to previous studies $^{15,24-26}$. This indicates that premature loss is due to poor oral hygiene, not related to children sex. Comparison of a study conducted in Brazil by Almeida-Heilborn et al., ${ }^{10}$, there was a significant difference between the sexes, with premature loss being more in males than in females. This may be a result of a prolonged period of feeding male infants due to a preference for sons which could be a causative factor for the high incidence of decay-filled (dft) scores among male individuals leading to increased loss of primary molars in a male individual as confirmed by Saravanan et al. ${ }^{27}$. There was a decrease in the prevalence of premature loss of primary teeth at 10 years $(17.7 \%)$, while the rate increased to $29.7 \%$, $31.6 \%$, and $31.7 \%$ in children aged 6,7 and 9 years, respectively (Table 2) which confirms the result reported by previous studies ${ }^{\mathbf{6 , 9 , 1 6}}$. In this study the teeth more frequently lost was 84 (the right lower molar) with (17\%), followed by 74 (the lower left primary molar) with (16\%), which was consistent with studies conducted by many researchers in the developing countries ${ }^{6,15,16,26,28}$. Because the first primary molars erupt early and stay in the oral environment for a longer period. These teeth are more prone to tooth decay. Moreover, dentists usually prefer to preserve the second primary molar to prevent space loss during the eruption of the first permanent molar. This explains why the first primary molars are more commonly extracted compared to the second primary molar, which leads to repeated early loss of the primary first molars ${ }^{29}$. The colonization of mutant streptococci is the main cause of early loss of primary molars. Increase of the mutant streptococcus colony towards primary molars due to anatomy of the occlusal fissured surface in nature and the proximal concave surface ${ }^{30}$. Compared to the study carried out in Romania by Andronic ${ }^{31}$, the tooth most affected by premature loss was the second primary molar of the mandible. This difference may be the result that each group has its own characteristics depending on the region in which you live and the health education. In this study, premature loss of only one tooth constituted the highest percentage of the total study group agreed upon with a study conducted by Al-Asadi ${ }^{32}$. In this study, the mandibular arch had more premature loss of the primary teeth than the upper jaw, which is similar to previous studies conducted in developing countries $^{6,15,22,28,31}$. The increased rate of premature loss of primary teeth in the mandibular arch may be due to food packaging and plaque accumulation compared to the abundance of saliva and its anticarious effect on the maxillary molar teeth ${ }^{16}$. The current study showed that the greater loss of primary teeth in the right quadrant of both jaws than in the left quadrant is consistent with other studies conducted by Ahmed et al., ${ }^{15}$ and Ayachandar et al., ${ }^{26}$. Due to the reduced level of cleaning and chewing powers, this leads to plaque accumulation on the right side, as emphasized by Lotto $^{33}$ and Park et al., ${ }^{34}$.

Table 6: Distribution of premature loss according to dental quadrant among male and female children aged 610 years.

\begin{tabular}{lllllll}
\hline \multirow{2}{*}{ Dental quadrant } & \multicolumn{6}{c}{ Gender } \\
\cline { 2 - 7 } & \multicolumn{2}{l}{ Male (561) } & \multicolumn{5}{c}{ Female (530) } & Total (1091) & \\
\hline \multirow{3}{*}{ Maxilla (right) } & 67 & 11.9 & 45 & 8.5 & 112 & 10.3 \\
Maxilla (left) & 53 & 9.4 & 42 & 7.9 & 95 & 8.7 \\
Mandible (right) & 89 & 15.9 & 82 & 15.5 & 171 & 15.7 \\
Mandible (left) & 92 & 16.4 & 73 & 13.8 & 165 & 15.1 \\
Total & 301 & 53.6 & 242 & 45.7 & 543 & 49.8 \\
\hline
\end{tabular}

\section{CONCLUSION}

The prevalence of premature loss is similar or roughly lower the rate in developing countries, the rate was low in 10 years children, while the rate raised in 6,7 , and 9 years; and most of the loss in dental arch was in mandible and the most common missing tooth was the right lower first primary molar. This result determines the importance of raising awareness about this problem and focusing on the need for more preventive efforts to maintain healthy and natural teeth that improve the chewing function and aesthetic appearance of children and the entire population.

\section{AUTHOR'S CONTRIBUTION}

This research work is part of a Master's thesis. The candidate is Kadija Ahmed Omer Bamashmoos to conduct clinical, field works and thesis. Corresponding author (HAA), second author (AHA), and the rest of the authors supervised the work, revised and edited the thesis draft and the manuscript. 


\section{ACKNOWLEDGEMENTS}

Authors acknowledge the financial support of Sana'a University, and Alhasani clinic and Dental Center in IBB City, Yemen.

\section{CONFLICT OF INTEREST}

No conflict of interest associated with this work

\section{REFERENCES}

1. AL-Awadi TAM, AL-Haddad KA, Al-labani MA, AlShamahy HA. Prevalence of malocclusion among Yemeni children of primary schools. Universal J Pharm Res 2019; 5(1): 1-6. https://doi.org/10.22270/ujpr.v5i1.355

2. Ulrahman MAASA, Yahya A, Al-Shamahy HA, Abbas AKMA. Occurrence of retromolar canal among a sample of Yemeni adults obtained from cone-beam computed tomography. Int Res J Med Med Sci 2020; 8(2): 35-41.

3. Alhadi Y, Rassem AH, Al-Shamahy HA, Al-Ghaffari KM. Causes for extraction of permanent teeth in general dental practices in Yemen. Universal J Pharm Res 2019; 4(2): 1-5. https://doi.org/10.22270/ujpr.v4i2.249

4. Mutaher NJA, AL-Haddad KA, Al-Akwa AAY, Al-labani MA, Al-Shamahy HA, Zabara AQMQ, Al- deen HMS. Prevalence and causes of traumatic dental injuries to anterior teeth among primary school children in Sana'a city, Yemen. Universal J Pharm Res 2020; 5(3):38-43. https://doi.org/10.22270/ujpr.v5i3.414

5. Al-Shahrani N, Al-Amri A, Hegazi F, Al-Rowis K, AlMadani A, Hassan KS. The prevalence of premature loss of primary teeth and its impact on malocclusion in the Eastern Province of Saudi Arabia. Acta Odontologica Scand 2015; 73(7): 544-549. https://doi.org/10.3109/00016357.2014.939709

6. Cavalcanti AL, Alencar CRBD, Bezerra P, GranvilleGarcia AF. Prevalence of early loss of primary molars in school children in Campina Grande, Brazil. Pakistan Oral Dent J 2008; 28(1): 113

7. Kronfeld R. Development and calcification of the human deciduous and permanent dentition. Bur 1935; 15: 18-25.

8. Borum MK, Andreasen JO. Sequelae of trauma to primary maxillary incisors. I. Complications in the primary dentition. Endodontics Dent Traumatol 1998; 14(1): 31-44. https://doi.org/10.1111/j.1600-9657.1998.tb00806.x

9. Cardoso L, Zembruski C, Femandes DS, Boff IPV, Pessin $\mathrm{V}$. Evaluation of prevalence of malocclusion in relation to premature loss of primary teeth. Pesq Bras Odontoped Clin Integr 2005; 5:17-2.

10. Almeida Heilborn JC, Küchler EC, Fidalgo DS, et al. Early primary tooth loss: prevalence, consequence and treatment. Int J Dent 2011; 10(3):126-130.

11. Yarmohammadi R, Mortazavi H, Rahmani A, Rahmani S. Tooth loss related to systemic disease. Int J Med Rev 2015; 2(4): 331-337.

12. Ceranić I. Position holders in the prevention of consequences of premature loss of primary teeth. Acta Stomat Croat 1990; 24(3):209-215. PMID: 2131751

13. Liegeois F, Limme M. Space maintenance following the premature loss of temporary teeth. Revue Belge de Medecine Dentaire 1992; 47(1):9-22. PMID: 1410703

14. Northway WM. The not-so-harmless maxillary: Primary first molar extraction. The J American Dent Assoc 2000; 131(12):1711-1720. https://doi.org/10.14219/jada.archive.2000.0117

15. Ahamed SS, Reddy V, Krishnakumar, et al. Prevalence of early loss of primary teeth in 5-10-year-old school children in Chidambaram town. Contem Clin Dent 2012; 3(1):27. https://doi.org/10.4103/0976-237X.94542

16. Alamoudi N. The prevalence of crowding, attrition, midline discrepancies and premature tooth loss in the primary dentition of children in Jeddah, Saudi Arabia. The J Clin Ped Dent 1999; 24(1):53-58. PMID: 10709544

17. Freeman JD. Preventive and interceptive orthodontics: a critical review and the results of a clinical study. The $\mathrm{J}$ Prevent Dent 1977; 4(5): 7.

18. Alsheneifi T, Hughes CV. Reasons for dental extractions in children. Ped Dent 2001; 23(2):1-5. PMID: 11340717

19. Bani M, Akal N, Bodur H, et al. The reasons for extractions of primary teeth in Turkish children. European J Paed Dent: Off J European Acad Paed Dent 2015; 16(3), 187-190. PMID: 26418919

20. Sahibzada HA, Munir A, Siddiqi KM, Baig MZ. Pattern and causes of tooth extraction in patients reporting to a teaching dental hospital 2016; 5(4):172-176. https://jimdc.org.pk/index.php/JIMDC/article/view/125

21. Galicia-Sosa A, Hernández-Guerrero JC, Jimenez-Farfan, M, Ledesma-Montes C. Reasons for primary teeth extraction in Mexican children. Boletin Medico-Hospital Infantil De Mexico 2003; 60(2):184-188.

22. Petcu A, Balan A, Maxim A. Current tendencies of the prevalence of the premature loss of the primary molars. J Romanian Med Dent 2009; 13(4):128-130.

23. Pedersen J, Stensgaard K, Meesen B. Prevalence of malocclusion in relation to premature loss of primary teeth. Comm Dent Oral Epidemiol 1978; 6(4): 204-209. https://doi.org/10.1111/j.1600-0528.1978.tb01151.x

24. Murshid S, Al-Labani M, Aldhorae K, Rodis O. Prevalence of prematurely lost primary teeth in 5-10-year-old children in Thamar city, Yemen: A cross-sectional study. J Int Soc Prev Comm Dent 2016; 6(8):S126-S130. https://doi.org/10.4103/2231-0762.189739

25. López-Gómez SA, Villalobos-Rodelo JJ, Ávila-Burgos L, et al. Relationship between premature loss of primary teeth with oral hygiene, consumption of soft drinks, dental care, and previous caries experience. Scientific Reports 2016; 6, (21147):1-7. https://doi.org/10.1038/srep 21147

26. Jayachandar D, Gurunathan D, Jeevanandan G, et al. Prevalence of early loss of primary molars among children aged 5-10 years in Chennai: A cross-sectional study. J Indian Soc Pedod Prev Dent 2019; 37(2):115.

27. Saravanan S, Kalyani V, Vijayarani M, et al. Caries prevalence and treatment needs of rural school children in Chidambaram Taluk, Tamil Nadu, South India. Indian J Dent Res 2008; 19(3):186. https://doi.org/10.4103/0970-9290.42948

28. Reddy NV, Daneswari V, Shruti G, et al. Premature loss of primary teeth on arch dimensions in 6-10-year-old schoolchildren in Khammam town, Telangana state. Int $\mathbf{J}$ Pedod Rehab 2018; 3(2): 67

29. Ockell NM, Bågesund M. Reasons for extractions, and treatment preceding caries-related extractions in 3-8 yearold children. European Arch Paed Dent 2010; 11(3):122130. https://doi.org/10.1007/BF03262727

30. Caufield PW, Cutter GR, Dasanayake AP. Initial acquisition of mutans streptococci by infants: evidence for a discrete window of infectivity. J Dent Res 1993; 72(1): 3745. https://doi.org/10.1177/00220345930720010501

31. Andronic A. Prevalence of early loss of primary teeth in 610 year old school children in Sibiu. Acta Medica Transilvanica 2017; 22(4):128-129.

32. Al-Assadi AH. Patterns and causes of teeth extraction among children attending Baghdad dental teaching hospital. Int J Med Res Health Sci 2018; 7(5):88-95.

33. Loto AO. Relative prevalence of caries in first and second premolars in urban Nigerians. Tropical Dent J 1998; 21(84):23-26. PMID: 11372109

34. Park K, Jung DW, Kim JY. Three-dimensional space changes after premature loss of a maxillary primary first molar. Int J Paed Dent 2009; 19(6):383-389. https://doi.org/10.1111/j.1365-263X.2009.00990.x 